\title{
Notch effect of welded joint
}

\author{
Vladimír Chmelko ${ }^{1 *}$, Matúš Margetin $^{1}$, and Michal Harakal ${ }^{1}$ \\ ${ }^{1}$ Faculty of Mechanical Engineering, Department of Applied Mechanics and Mechatronics, Námestie slobody 17, 81231 Bratislava, \\ Slovakia
}

\begin{abstract}
In general, the welded joints are multifactorial notches. This study is focused to separate the geometrical influence (when the weld can be seen on the surface) and technological factors (internal defects of the weld, structural changes of the material and residual stress) on its fatigue life. Proposed methodology of this separation comes out from the cyclic test of three specimens - group with existing weld, group without weld joint (base material) and another group where was removed outer geometry of the weld.
\end{abstract}

\section{Page layout}

The weld joint has often the same strength as the strength of the base material. This statement does not apply at all to fatigue strength (Fig. 1). Euro code 3 „Design of steel structures“ states allowable stress amplitudes for different welding joints [1]. These values are significantly lower than the fatigue strength values at the harmonic loading of low-carbon structural steels. The reason is in the very essence of a welding joint - a joint that changes the structure of the material in the locality of the joint and its geometry. Notch effects of welds are a very wide problem [2-7]. In more detail, we will analyse the problem of two components of the notch effect of the welding joint.

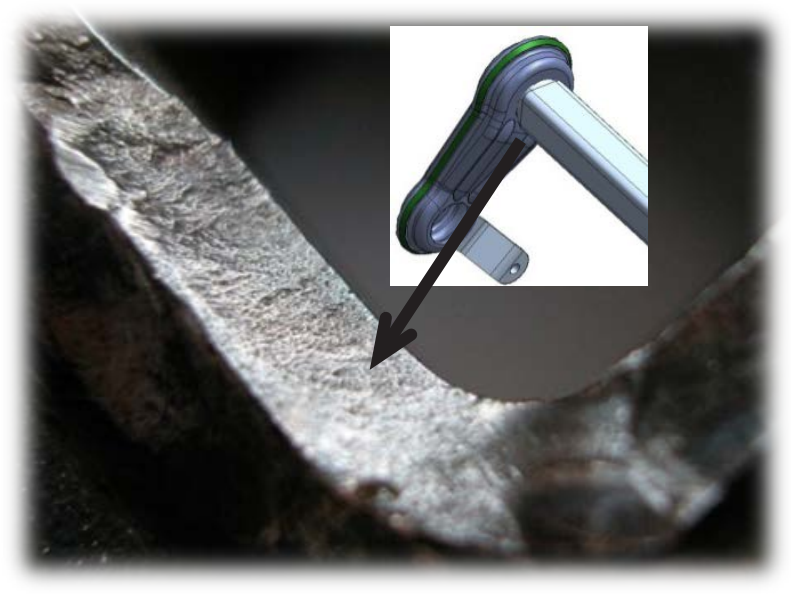

Fig. 1. Fatigue fracture caused by welding of the wheel arm with axle at high stress levels

From the fatigue strength assessment point, we can consider the weld joint as a stress and deformation concentrator, which contains two fatigue strength reducing sources and the lifetime of the structure [2]:
- As technological notch, we describe a subset of subsurface discontinuities (cracks, interstices, porosities, bubbles) and non-homogeneities of material like (structural changes, residual stresses ...) that negatively affect the fatigue behaviour of the weld joint - Fig. 2;

- As geometrical notch, we mean the sum of all surface geometrical irregularities (welding beads, surface welding errors) that create stress concentration and deformation on the free surface of the component, thereby reducing its fatigue strength.

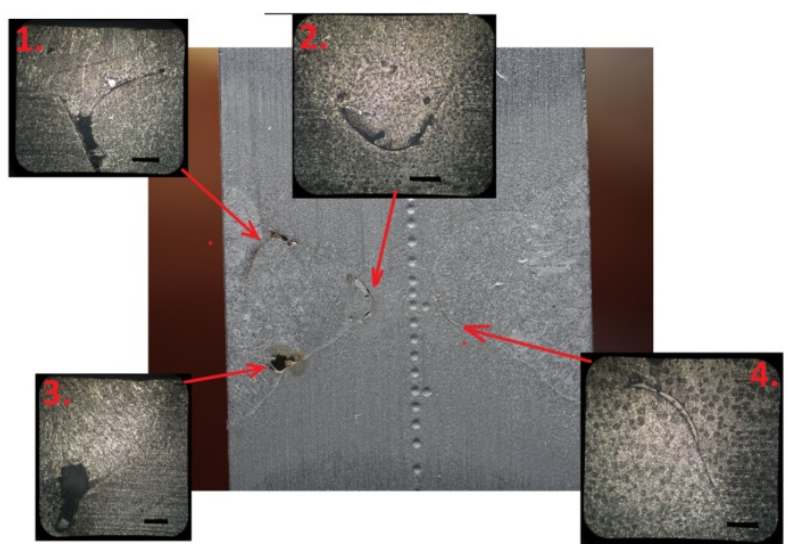

Fig. 2. Set of errors in the welding microstructure: top left recast error characterized by imperfect joining of two layers of weld bead; top right - imperfectly welded root of the weld (this error occurred due to too large a drop of weld metal at the beginning of the welding); bottom left - bubble in welding metal; Bottom right - inclusion between the weld metal and the base material

\section{The notch coefficient of the weld joint}

\footnotetext{
Corresponding author: vladimir.chmelko@stuba.sk
} 
The total notch coefficient of the weld joint can be defined by comparing the fatigue curves at the Fig. 3.-5. in the following shape

$$
\beta_{\sigma(2 N f)}=\frac{\sigma_{a(2 N f)}^{H}}{\sigma_{a(2 N f)}^{Z V}},
$$

where $\sigma_{a(2 N f)}$ is a stress amplitude corresponding to chosen number of cycle to the fracture of the base material specimen,

$\sigma_{a(2 N f)}^{W}$ is a stress amplitude corresponding to a certain number of cycles to the fracture of specimen with the weld joint.

For three different welds, cyclic test of the samples were performed in two separated groups (Fig. 3) :

- $\quad$ specimens with the weld joint in the middle

- $\quad$ specimens of base material

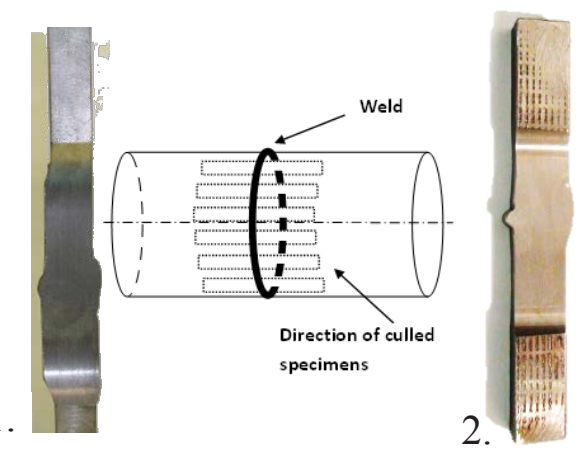

3.

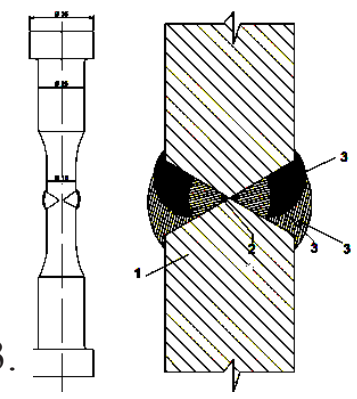

Fig. 3 The expertise of three type of welds

The first set was the specimens from end V-weld culled directly from courtyard of pipe DN700 of the transit gas pipeline. The material represented the rolled pipeline steel the Mannesmann steel, equivalent with the steel St52. By gradual milling of the side faces, the test specimens were narrowed in the working part, with the original surface of the pipe retained on the front surfaces, with the welding on both sides. The obtained Basquin dependence for specimens with the weld joint and for base material of the pipeline are at the Fig.4.

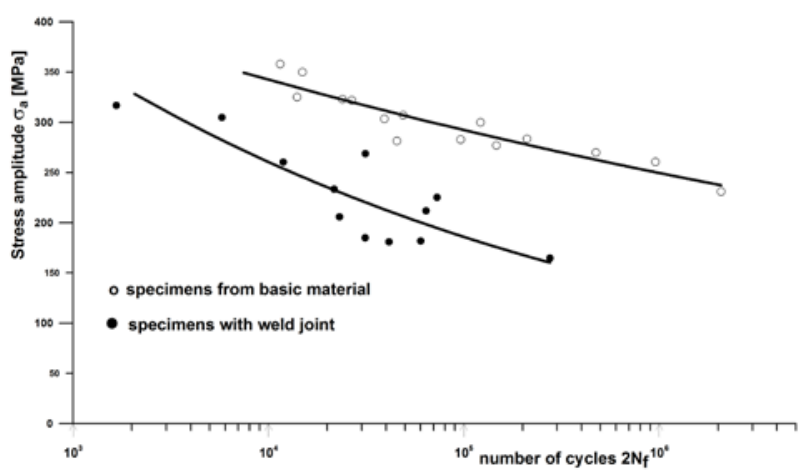

Fig. 4. Basquin dependency $\sigma_{a}=f(2 N f)$ [8] for smooth specimens of pipeline material (St 52) and specimens of pipeline with weld joint

From the regression lines in Fig. 4, was calculated the notch coefficient defined by Eq. 1 as the number of cycles to the fracture in the shape

$$
\beta_{\sigma}^{1}=0.64219\left(2 N_{f}\right)^{0.077767}
$$

From the graphical process at Fig. 5, it can be seen that the values of the notch effect in the region of $10^{4}$ cycles are about $\beta \approx 1,3$ and in the regions over the $10^{6}$ cycles reach and then gradually exceed the value $\beta \approx 2$.

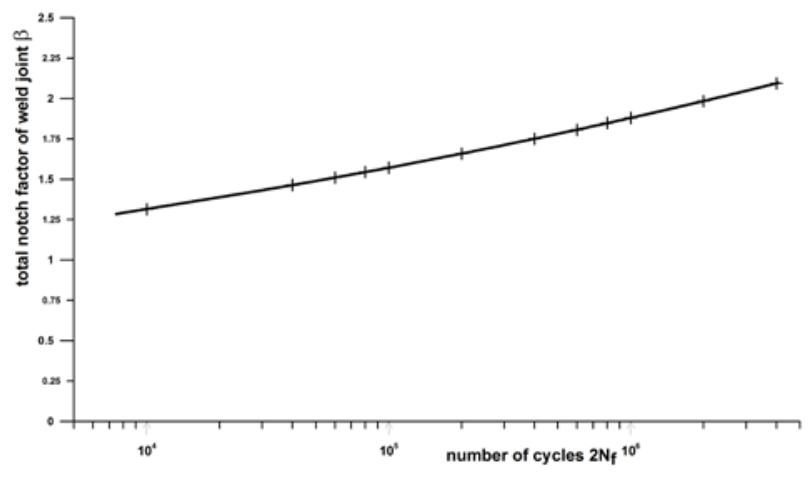

Fig. 5 Dependency of the notched effect of the pipe welding joint (St52) on the number of cycles to the fracture

The second set was a rounded V-weld made as the front weld of two cylindrical parts. The Basquin curves of the sample material and the samples with the weld in the middle of the working part are at the Fig.6.

Weld joint was made in two steps: first, the welding root was formed in its axis in a special preparation ensuring the consistency of the two cylindrical parts of the sample; in the second step, during continual rotation was made up the weld up to the outer cylindrical parts of the specimen, while the specimen was still in a special preparation maintaining the co-existence of the resulting sample with the weld. 


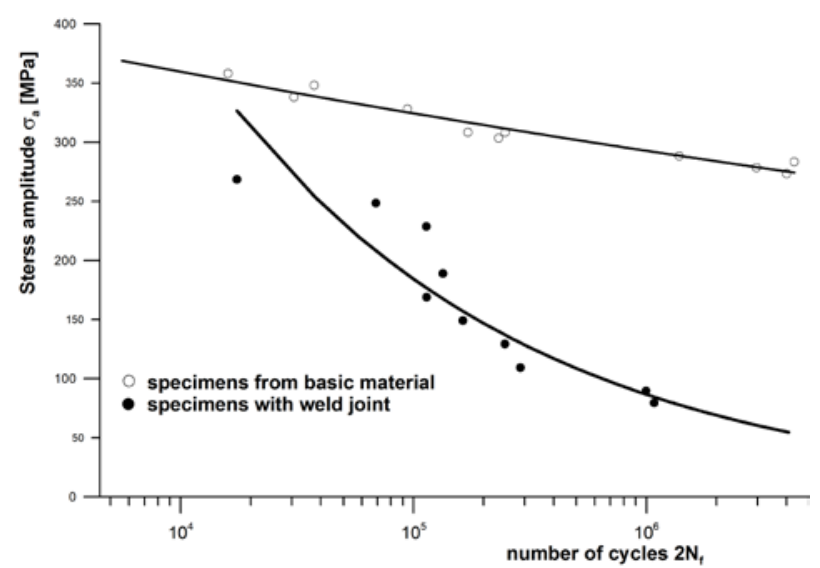

Fig. 6 The Basquin dependency $\sigma_{a}=f\left(2 N_{f}\right)$ for smooth specimens of steel and specimens with weld joint

From the regression lines in Fig. 6, was calculated the notch coefficient defined by Eq. 1, as the number of cycles to the fracture in the following shape

$$
\beta_{\sigma}^{2}=0.06768\left(2 N_{f}\right)^{0.283}
$$

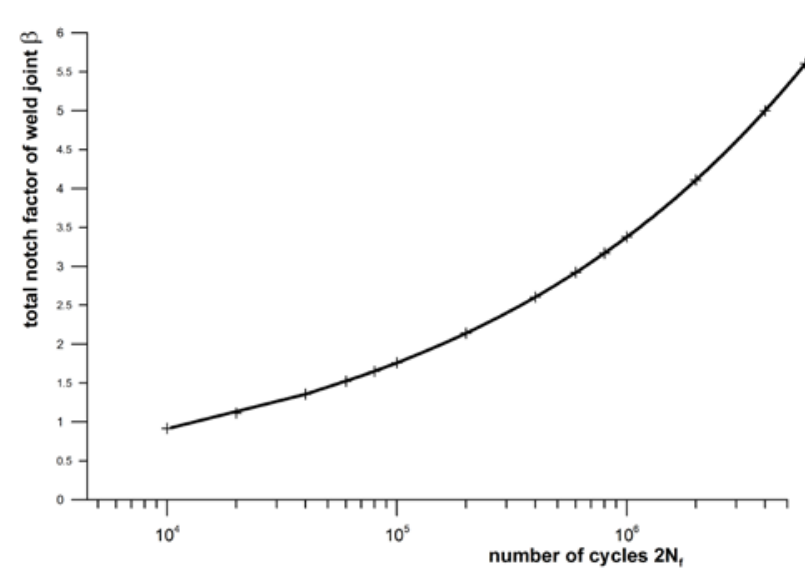

Fig.7 The dependency of notch effect of the V-weld weld to the number of cycles to fracture

From its graphical diagram Fig.7, it can be seen that the notch effect in region of $10^{4}$ cycles are about $\beta \approx 1$ (even smaller) and in regions over the $10^{6}$ cycles reach and then gradually exceed the value $\beta \approx 4$.

The third experimental set consisted of samples with a frontal V-weld, as well as Group 1. They were selected from the weld of two short sections of the pipeline DN500 in the longitudinal direction. The material represented the rolled pipeline steel that is equivalent with the steel S355J2. By gradual milling of the side faces, the test specimens were narrowed in the working part, with the original surface of the pipe retained on the front surfaces, with the welding on both sides. The obtained Basquin dependence for specimens with the weld joint and for sample of the base pipeline material are at the Fig.8.

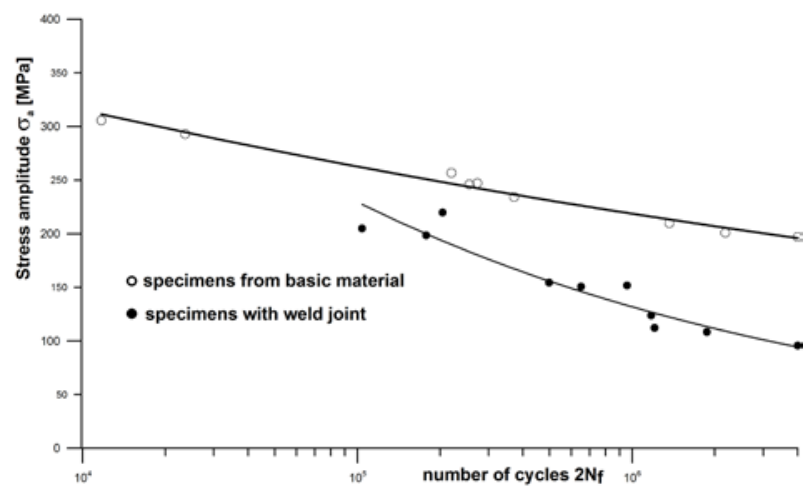

Fig. 8 The Basquin dependency $\sigma_{a}=f\left(2 N_{f}\right)$ for smooth specimens of steel with the weld join

From the regression line in Fig. 8, was calculated notch coefficient defined by Eq. 1 as the number of cycles to the fracture in the following form

$$
\beta_{\sigma}^{3}=0.17841\left(2 N_{f}\right)^{0.16137}
$$

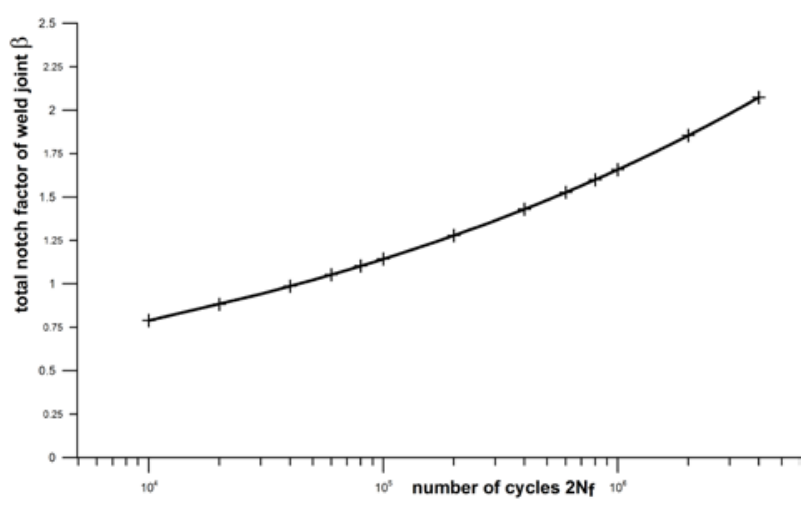

Fig.9 Dependency of notch effect of the V-weld weld joint to the number of cycles to the fracture

From its graphical process in Figure 9, it can be seen that the notch effect values in the region of $10^{4}$ cycles are about $\beta \approx 1$ (even smaller) and in regions over the $10^{6}$ cycles reach and then gradually exceed the value $\beta \approx 2$.

Comparison of the notch coefficients obtained by the above described processes for three different types of welds, depending on the number of cycles to the fracture, is shown in Figure 10. 


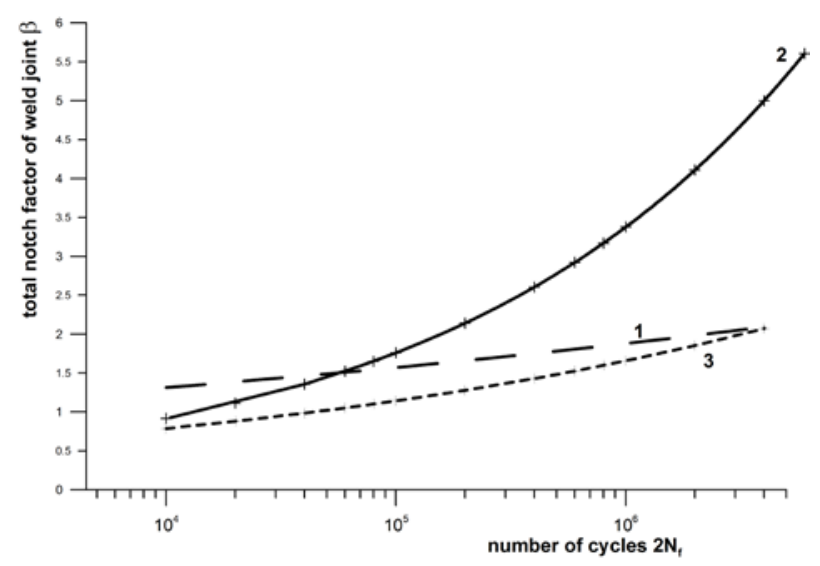

Fig. 10 Comparison of notch coefficients for three experimental sets: 1 - end V-weld culled directly from transit gas pipeline DN700; 2 - rounded V-weld; 3 - end V-weld culled from pipeline DN500 made special for this test

\section{Methodology of separation of the technological and geometric part of the welding joint}

The total notch coefficient of the weld joint can be expressed as the sum of two of its parts, where each of these parts has different physical cause, in the form

$$
\beta_{\sigma}=\beta_{\sigma, T}+\beta_{\sigma, G}
$$

where $\beta_{\sigma}$-total weld notch coefficient

$$
\begin{aligned}
& \beta_{\sigma, T}-\text { technological weld notch coefficient } \\
& \beta_{\sigma, G^{-}} \text {geometrical weld notch coefficient }
\end{aligned}
$$

The technological part of the notch is mainly caused by internal defects and the structure of the heataffected zone as a result of the welding joint manufacturing technology. The geometric part is caused by the classical concentration of the force flow at the point of the weld metal elevation relative to the base material.

The technological part of the notch effect can be influenced by the overall choice and parameters of the technological process. After its application on the welding process, the technological part of the friction effect on the fatigue life is already given. The geometrical part of the notch can be affected even after the welding joint has been created by additional surface treatment. Therefore, it may be useful in practice to know its size.

From the point of view of the methodology, it is necessary to create three groups of samples (fig. 11):

- specimens of base material (1)

- specimens with weld joint (2)

- specimens with removed geometry of weld joint (3)

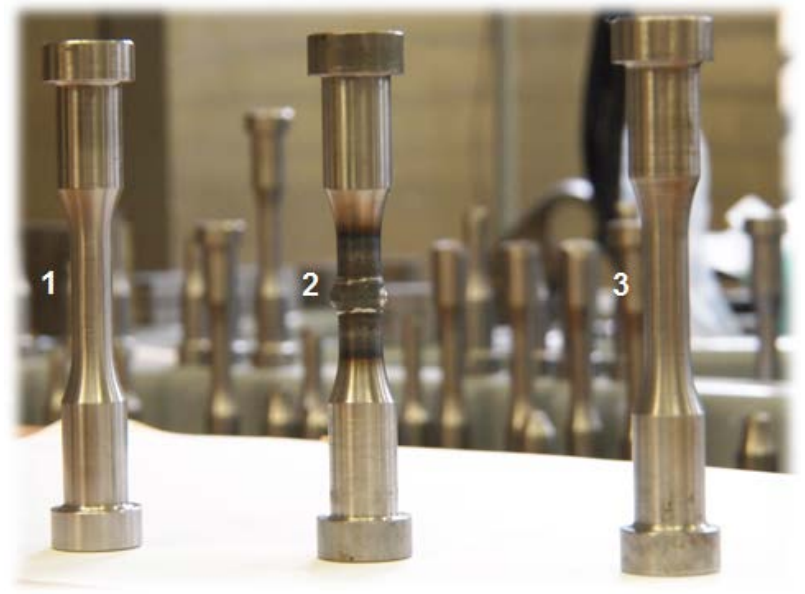

Fig. 11 The groups of specimens for separation of geometric and technological part of the notch.

The cyclic tests of such prepared specimen groups allow quantifying the individual notch effects. Fatigue curves of life in a mode with controlled force in the form of Basquin dependence $\sigma_{a}=f(2 N f)$ are displayed in Fig. 12 for the type of weld 2 (fig 3). Expect the longest fatigue life for the selected amplitude stress level $\sigma_{a}$ achieves smooth samples of the base material, the shortest life of the sample with the full notch effect of the weld. However, the effect of removing the geometric welding notch (dashed line) is positive - it is positive in regions of the high life cycles - above the intersection $\mathrm{P}$ (in this case approximately $1.6 \times 10^{5}$ cycles) or so called high-cycle fatigue. On the other hand, in the short life span, the effect of the removal of welding geometry is even negative and leads to shorter lifetimes than to untreated weld joints.

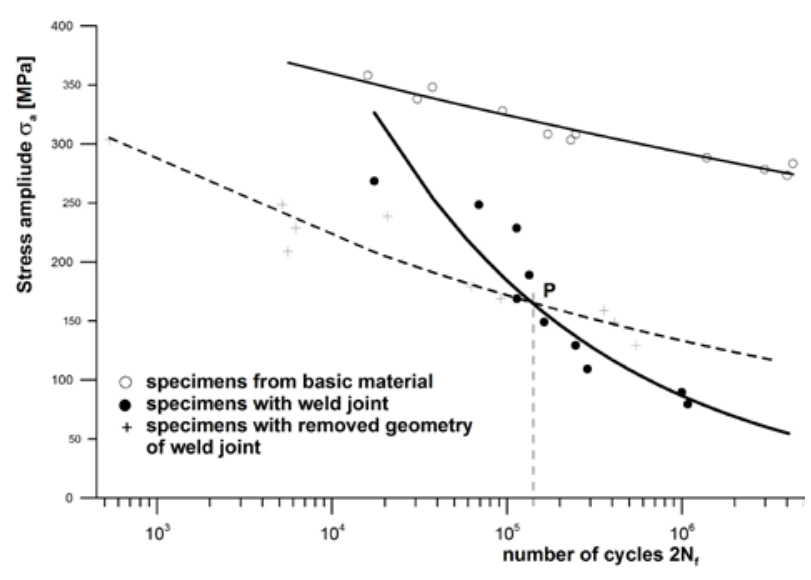

Fig. 12 Basquin curves $\sigma_{a}=f(2 N f)$ for welded specimens, specimens without weld and specimens with removed geometry of the weld

As shown in [9], it is possible to quantify and display the individual components of the overall notch effect of the weld joint, as shown in Fig. 13. 


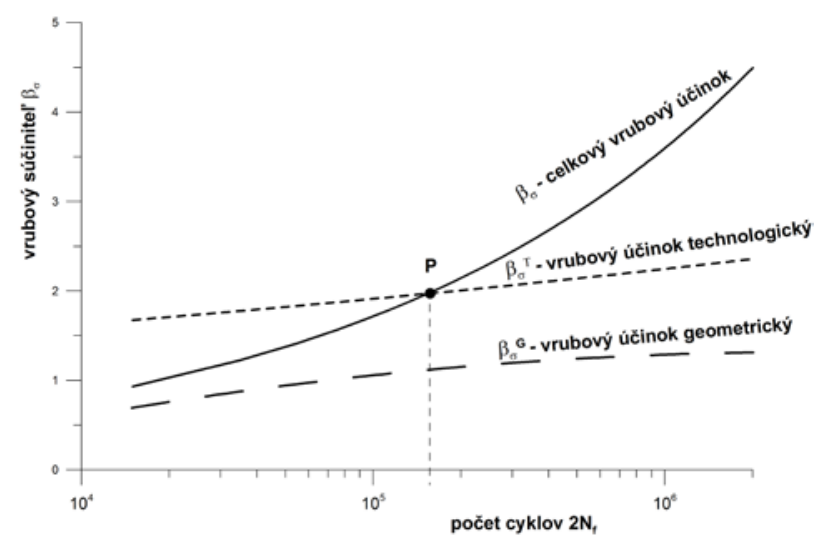

Fig. 13 Separation of individual notch effects of the weld joint 2 displayed in Fig.3

\section{Evaluation of results}

The study is devoted to three types of welding joints (Fig 3). For each weld joint, were obtained the Basquin dependency by experiment and compared with the same dependence obtained on the specimens of the correspondent base materials. In all three cases, the shortening of the fatigue life due to the welding was demonstrated only at a certain value of the amplitude load, not in its entire range. Likewise, the notched coefficients, expressed as a function of the number of cycles to the fracture, achieved more significant values, up to the number of orders $10^{3}$ i.e. $10^{4}$ cycles to the fracture. The notch effects of weld joints 1 and 3 exceeded the value 2 up to the regions of long fatigue lifetimes of the order $10^{6}$ cycles.

The presented methodology of cyclic test of three groups of specimens allowed the separation of the overall notch effect on its two main components technological and geometric. Results were obtained for weld type 2 (fig. 3 ).

The notch coefficient including the welding process factors is virtually constant throughout the lifetime $\left(\beta_{\sigma T} \cong 2\right)$. The notch coefficient including the influence of the welding geometry increases the overall notched impact effect of the weld only in the area of life above point $\mathrm{P}$ (so-called high-cycle fatigue). Under $\mathrm{P}$, that means. in the short lifetime, its values are less than 1 , that means reduces the overall notch effect of the weld. This surprising phenomenon may be due to the presence of local plastic deformations at the root of the welding geometry (high stress amplitudes) that lead to a decrease in the stress concentrator and the formation of pressure residual stresses in the welding heel. These factors positively influence the fatigue life and thus counteract the effect of technological factors [10].

This work was supported by the Research \& Development Operational Programme funded by the ERDF ITMS: 26240220084 Science city Bratislava.

\section{References}

1. Eurocode 3. Design of Steel Structures. Part 1-9: Fatigue. UNI ENV 1993-1-9. Brussels, CEN 2015

2. Radaj, D., Sonsino, C. M., Fricke, W.: Fatigue Assessment of Welded Joints by Local Approaches. $2^{\text {nd }}$ edt. , Woodhead Publishing Ltd. (2006)

3. Haagensen, P. J.: Fatigue Design ofWelded Structures

- Norsok and Eurocode 3. Trondheim, NTNU 2011.

4 Hobbacher, A. (Ed.).: Recommendations for Fatigue Design of Welded Joints and Components. Document IIW-1823-07, ex XIII-2151r4-07/XV-1254r4-07. Paris, International Institute of Welding 2008.

5. Hobbacher, A. F.: Int. J. Fatigue, 31, 2009, p. 50.

6.Margetin, M.: Contribution to Fatigue Life Time Evaluation of Welded Joints. [Ph.D. thesis]. Bratislava, Slovak University of Technology in Bratislava 2012

7. M. Kepka, M. Kepka, Jr., Calculations of fatigue life of a welded joint in the construction of the trolleybus rear axle. Proceedia Structural Integrity, 5, 103(2017), p. 1409-1416.

8. Basquin, O. H.: Proceedings ASTM, 10, 1910, p. 625.

9. V. Kliman, V. Chmelko, M. Margetin, Analysis of the notch effect of welded joint and of grinding effect. In Kovové materiály. Metallic materials. 53, 6 (2015), p. 429-441

10.Kliman, V. - Bílý, M. - Prohácka, J.: Int. J. Fatigue 15, 2 (1993), p. 93-107. 